\title{
Extraction of Clove and Vetiver Oils with Supercritical Carbon Dioxide: Modeling and Simulation
}

\author{
Julian Martínez*,1, Paulo T.V. Rosa ${ }^{2}$ and M. Angela A. Meireles ${ }^{*, 3}$ \\ ${ }^{1}$ EQA - CTC/UFSC (Federal University of Santa Catarina), Cx. P. 476, 88040-900, Florianópolis, SC, Brazil \\ ${ }^{2}$ Institute of Chemistry - UNICAMP (State University of Campinas), Cx. P. 6154, 13083-862, Campinas, SP, Brazil \\ ${ }^{3}$ LASEFI - DEA / FEA - UNICAMP (State University of Campinas), Cx. P. 6121, 13083-970, Campinas, SP, Brazil
}

\begin{abstract}
The kinetics of supercritical fluid extraction (SFE) of clove and vetiver oils using carbon dioxide as solvent was studied, in order to establish an efficient method to predict extraction curves on large scale. The mass transfer model of Sovová was used to adjust the experimental SFE data, which were obtained at 100 bar and $35{ }^{\circ} \mathrm{C}$ for clove and 200 bar and $40{ }^{\circ} \mathrm{C}$ for vetiver, using extraction columns of different geometry and solvent flow rates. Some other process parameters, such as bed density and porosity, solvent to feed ratio and solvent velocity were kept constant from one experiment to another, in order to verify if the mass transfer coefficients adjusted by the model varied. The results show that the model of Sovová was able to predict an overall extraction curve for clove from data obtained with twenty times less raw material, since the mass transfer coefficients remained the same and the predicted curves were similar to the observed ones. For vetiver, the simulation was not as effective, probably due to the effects of transport properties on the process.
\end{abstract}

\section{INTRODUCTION}

The supercritical fluid extraction (SFE) process is based on the contact between a solid raw material and a pressurized solvent, which removes the compounds of interest from the solid phase. After this removal, the extract is separated from the solvent through pressure reduction at low temperature.

The optimization of operational conditions used in SFE is of great importance to make this technique economically viable, since the investment to build a SFE unit is high when compared to conventional methods [1]. The mathematical modeling of experimental data of SFE has the objective to determine parameters for process design, such as equipment dimensions, solvent flow rate and particle size, in order to make the estimation of the viability of SFE processes in industrial scale, through the simulation of overall extraction curves (OECs). Many models for SFE OECs have been proposed, being them empirical [2] or based on the mass balance inside the extraction bed. In this case, each author gives his own interpretation of the mass transport phenomena that happen during the process, in order to solve the differential mass balance equations, obtaining the OECs. One of these models was proposed by Sovová, who applies the broken and intact cell concept [3].

The model of Sovová [3], as well as other models from the literature $[4,5]$, often presents good results when used to fit to SFE experimental data, but few authors have effectively tried to establish a methodology to use the models to predict processes in other conditions, like larger scale. The influence of some process conditions on the extraction yields $[6,7]$ and rates $[8,9,10]$ were studied, but not with the direct objective of scaling-up the SFE process.

*Address correspondence to these authors at the EQA - CTC/UFSC (Federal University of Santa Catarina), Cx. P. 476, 88040-900, Florianópolis, SC, Brazil; Tel: 5548 3721.9448; Fax: 5548 3721.9687; E-mail: julian@enq.ufsc.br

LASEFI - DEA / FEA - UNICAMP (State University of Campinas), Cx. P. 6121, 13083-970, Campinas, SP, Brazil; Email: meireles@fea.unicamp.br
Clove (Eugenia caryophillus) is a native plant from Indonesia, which was spread to other tropical regions of the planet. Clove oil is rich in eugenol, which is used in the manufacturing of pharmaceutical products and by dentists. In food industry, clove oil is used as aroma, and may be also applied as anti-microbial agent in meat products and cheese [11]. In SFE with $\mathrm{CO}_{2}$ as solvent, clove has been used as a model for kinetic and thermodynamic studies of SFE systems, due to its richness in volatile oil (about 15\%), which is composed by basically four substances. Eugenol is the main compound in clove oil, representing over $50 \%$ of the total extract composition [12]. Other compounds found are $\beta$ caryophyllene, $\alpha$-humulene and eugenyl acetate. Volatile oils extracted from other vegetable raw materials may have hundreds of different compounds, so clove oil, with its quite simple compositions, can be treated in SFE modeling as a single pseudo-compound.

Vetiver (Vetiveria zizanioides (L.) Nash ex Small) is found in tropical regions of the planet, such as India, China, Indonesia, Haiti and the Reunion Island, who are the world main vetiver oil producers. In Brazil, the vetiver oil production is still low, because of a great variability of the product price and quality.

The volatile oil from vetiver roots is a viscous liquid at ambient temperature. Its color varies from amber to dark brown, and whose odour has sweet, earthy and woody notes [13]. This oil is appreciated by the perfume industry, where it is used as fixative and as odour contributor in bases, such as rose [14] and chypre [15], and in several masculine fragrances. Besides its applications in perfume and cosmetic products, vetiver oil can also be used in aromatherapy [16] and in food, as aroma in canned products [17] and flavor agent in beverages [18].

Unlike clove oil, vetiver oil has a quite complex composition, including substances from various chemical functions, such as hydrocarbons, alcohols, ketones and acids, mainly with sesquiterpenic structures [20]. 
The objective of this work was to establish a methodology to predict SFE curves in large scale, departing from data obtained in small scale experiments. This methodology should specify which scale-up criteria must be applied in order to reproduce small scale curves in large scale SFE processes.

\section{MATERIALS AND METHODS}

\section{Raw Material}

\section{Clove Buds}

Clove buds grown in the state of Bahia, in northeastern Brazil were purchased in the municipal market of Campinas (Brazil). The raw material was cleaned, triturated, separated by particle size and stored [19]. The clove bud particles with mean Sauter diameter of $8.6 \times 10^{-4} \mathrm{~m}$ were selected for the SFE experiments. The chosen operational conditions were pressure of 100 bar and temperature of $35^{\circ} \mathrm{C}$, when the solvent is supercritical and solubility data was available for clove oil [19].

\section{Vetiver Roots}

Vetiver roots were purchased from a local producer in the state of São Paulo, Southeastern Brazil. The roots were dried, milled and separated by particle size, as described by Martínez et al. [20]. The particles with mean diameter lower than $1.8 \times 10^{-4} \mathrm{~m}$ were selected to the extraction procedures.

\section{Determination of the Total Amount of Extractable Mate- rial (Global Yield)}

In order to obtain the global yield at the chosen operational conditions, a previous experiment was performed for each raw material, using a ratio between $\mathrm{CO}_{2}$ mass flow rate and feed mass high enough to extract all the solute from clove buds in one hour and from vetiver roots in two hours. The mass of solid used in these experiments was $(4.04 \pm$ $0.01) \times 10^{-3} \mathrm{~kg}$ of clove buds and $(3.52 \pm 0.02) \times 10^{-3} \mathrm{~kg}$ of vetiver roots. The operational conditions were $100 \mathrm{bar}$ and $35{ }^{\circ} \mathrm{C}$ for clove, for which all necessary data for the mathematical modeling was available [19]; and 200 bar and $40^{\circ} \mathrm{C}$ for vetiver SFE, for which best yields were achieved [20].

The raw material was packed into a $5 \mathrm{~mL}$ stainless steel column (Thar Designs, CL1165, Pittsburgh, USA). The extremities of the column were covered with polypropylene wool, to avoid solid particles from entering the extraction line. The column was closed and connected to a SFE system (Applied Separations, Spe-ed SFE, Allentown, USA), where SFE was performed.

The extract was collected during one hour (clove) and two hours (vetiver) in a glass flask immersed in an ice bath to reduce the loss of the more volatile compounds. The line between the column and the outlet valve was rinsed with ethanol (99.8\% P.A. Merck, Campinas, Brazil), which was removed using a rotovap (Heidolph Instruments, model Laborota 4001, Viertrieb, Germany) with vacuum control (Heidolph Instruments, model Rotavac, Viertrieb, Germany) in order to obtain the pure extract.

The extracts obtained during the SFE process were weighed in an analytical balance (Sartorius Analytical, model A200S, Gottingen, Germany) and the extraction yield was calculated from the total mass in terms of $\mathrm{X}_{0}$ (mass of extract/mass of dry raw material).

\section{Kinetic Experiments}

The kinetic SFE experiments were performed at the same equipment, so the basic procedure was the same as described for the global yield determination. Instead of using one glass flask, many glass flasks were used to collect the extracts, in order to measure the mass extracted in defined time intervals and then build the extraction curves. At each 5 or 10 minutes of extraction, the flask was changed by an empty one. All the empty flasks were weighed before each experiment. After the pressure reduction, the SFE line between the column and the micrometer valve was washed with ethanol (99.8\% P.A. Merck, Campinas, Brazil). The ethanol was evaporated under vacuum and the extract amount that remained in the line was weighed.

Kinetic experiments were performed in small and large scales for both clove and vetiver oil extractions. The kinetic clove oil SFE experiments were performed at 100 bar and 35 ${ }^{\circ} \mathrm{C}$. For SFE from vetiver roots, the experiments were performed at 200 bar and $40{ }^{\circ} \mathrm{C}$. $\mathrm{CO}_{2}$ mass flow rates were fixed according to the required scale-up criteria.

\section{Small Scale Experiments}

The SFE experiments at small scale were performed using a $5 \mathrm{~mL}$ column, the same used in the experiments for the determination of $\mathrm{X}_{0}$. The extractions were carried out for 100 minutes for clove and 140 minutes for vetiver. $\mathrm{CO}_{2}$ flow rate was measured with an analog flow totalizer $(0.02 \mathrm{~L}, \mathrm{LAO}$, model G-1, Brazil).

\section{Large Scale Experiments}

In order to make comparison possible, the same set of raw materials were used in both small and large scale experiments. The operational conditions (pressure and temperature) were also preserved, as well as particle size, bed density and porosity. Two scale-up criteria were tested for SFE from clove buds and vetiver roots:

1) Keeping the velocity of the solvent in the SFE bed constant;

2) Keeping the residence time of the solvent in the SFE bed constant.

A $300 \mathrm{~mL}$ stainless steel column (Thar Designs, CL1373, Pittsburgh, USA) was used for the large scale experiments. Tables $\mathbf{1}$ and $\mathbf{2}$ show the process parameters used for small and large scale experiments for clove and vetiver, respectively.

To keep the solvent velocity constant, the $\mathrm{CO}_{2}$ flow rate was increased proportionally to the area of the bed's transversal section. Then, the superficial velocity, v, was preserved as shown in equation (1), where $\mathrm{Q}_{\mathrm{CO} 2}$ is the solvent flow rate and $\mathrm{A}$ is the area of the bed's transversal section. Since the bed porosity was kept constant, the interstitial velocity was also constant.

$\mathrm{v}=\frac{\mathrm{Q}_{\mathrm{CO}_{2}}}{\mathrm{~A}}$

The large scale experiments with constant $\mathrm{CO}_{2}$ velocity took 90 minutes for clove oil extraction, and 140 minutes for 
SFE from vetiver roots. These times should be enough to deplete over $90 \%$ of the extractable material from the solids, in order to obtain a complete extraction curve.

In a second trial of establishing scale-up parameters, SFE was performed using the same residence time of the solvent inside the extraction bed as in the small scale experiments. This was possible by keeping the ratio between height and diameter of the extraction bed constant, and by increasing the $\mathrm{CO}_{2}$ flow rate in the same proportion as the mass of raw material. The residence time can be calculated by equation (2), where $\mathrm{V}_{\mathrm{B}}$ is the bed volume; $\varepsilon$, the porosity; $\rho$, the $\mathrm{CO}_{2}$ density; $\mathrm{Q}_{\mathrm{CO} 2}$, the $\mathrm{CO}_{2}$ mass flow rate; $\mathrm{d}_{\mathrm{B}}$, the bed diameter; $\mathrm{H}_{\mathrm{B}}$, the bed height.

$\mathrm{t}_{\mathrm{res}}=\frac{\mathrm{V}_{\mathrm{B}} \mathcal{\varepsilon} \rho}{\mathrm{Q}_{\mathrm{CO} 2}}=\frac{\pi \mathrm{d}_{\mathrm{B}}^{2} \mathrm{H}_{\mathrm{B}} \mathcal{\varepsilon} \rho}{4 \mathrm{Q}_{\mathrm{CO} 2}}$

\section{Mathematical Modeling}

The mathematical model of Sovová [3] was applied to the experimental OECs, with the help of a global optimization tool that combines a lexicographical grid search with a Local Variation approach and the Nelder-Mead procedure to refine the final approximation [21]. The mass transfer coefficients $\left(\mathrm{k}_{\mathrm{YA}}\right.$ for the fluid phase and $\mathrm{k}_{\mathrm{XA}}$ for the solid phase) adjusted with the model for the small scale experiments were used to simulate OECs at the large scale conditions. The simulated OECs were then compared to experimental large scale data, to evaluate scale-up effectiveness.

According to the model of Sovová [3] the supercritical solvent flows axially through a cylindrical extraction bed. At the bed inlet the solvent is solute-free. The initial solute distribution and particle size are taken as homogeneous. However, part of the solute is directly exposed to the solvent, due to cell wall braking in the milling of the raw material. The other part of the solute remains inside cell walls, so diffusion is required to make its contact with the solvent possible. Based in these suppositions, the SFE process can be divided in three steps: the first one, when only the easily accessible solute is removed, is controlled by convection in fluid phase; the second, where both convection and diffusion are important; and the third step, when the only solute remaining is inside the cell walls, is controlled by diffusion in solid phase. Sovová [3] solved the mass balance equations for both fluid and solid phases, leading to the following equations to represent the OECs:

$$
\begin{aligned}
& \mathrm{m}\left(\mathrm{h}=\mathrm{H}_{\mathrm{B}}, \mathrm{t}\right)=\mathrm{Q}_{\mathrm{CO}_{2}} \mathrm{Y}^{*}[1-\exp (-\mathrm{Z})] \mathrm{t} \\
& \mathrm{m}\left(\mathrm{h}=\mathrm{H}_{\mathrm{B}}, \mathrm{t}\right)=\mathrm{Q}_{\mathrm{CO}_{2}} \mathrm{Y}^{*}\left[\mathrm{t}-\mathrm{t}_{\mathrm{CER}} \exp \left(\mathrm{Z}_{\mathrm{w}}-\mathrm{Z}\right)\right] \\
& \mathrm{m}\left(\mathrm{h}=\mathrm{H}_{\mathrm{B}}, \mathrm{t}\right)=\mathrm{m}_{\mathrm{SI}}\left\{\mathrm{X}_{0}-\frac{\mathrm{Y}^{*}}{\mathrm{~W}} \ln \left[1+\exp \left(\frac{\mathrm{WX}_{0}}{\mathrm{Y}^{*}}\right)-1\right] \exp \left[\frac{\mathrm{WQ}_{\mathrm{CO}_{2}}}{\mathrm{~m}_{\mathrm{SI}}}\left(\mathrm{t}_{\mathrm{CER}}-\mathrm{t}\right)\right]\left(\frac{\mathrm{X}_{\mathrm{k}}}{\mathrm{X}_{0}}\right)\right\}
\end{aligned}
$$

Where:

$$
\begin{gathered}
Z=\frac{m_{S I} k_{Y A} \rho}{Q_{C O_{2}}(1-\varepsilon) \rho_{s}} \\
W=\frac{m_{S I} k_{X A}}{Q_{C_{2}}(1-\varepsilon)}
\end{gathered}
$$

$\mathrm{Z}_{\mathrm{w}}=\frac{\mathrm{ZY^{* }}}{\mathrm{WX}_{0}} \ln \left\{\frac{\mathrm{X}_{0} \exp \left[\frac{\left.\mathrm{WQ}_{\mathrm{CO}_{2}}\left(\mathrm{t}-\mathrm{t}_{\mathrm{CER}}\right)\right]-\mathrm{X}_{\mathrm{k}}}{\mathrm{m}_{\mathrm{SI}}}\right.}{\mathrm{X}_{0}-\mathrm{X}_{\mathrm{k}}}\right\}$

$t_{C E R}=\frac{m_{S I} X_{p}}{Y * Z Q_{C O_{2}}}$

$t_{F E R}=t_{C E R}+\frac{m_{S I}}{Q_{C O_{2}} W} \ln \left[\frac{X_{k}+X_{p} \exp \left(W X_{0} / Y *\right)}{X_{0}}\right]$

The needed data to apply the model of Sovová [3] are: $\mathrm{X}_{0}$, bed porosity, solid and $\mathrm{CO}_{2}$ densities $\left(\rho_{\mathrm{s}}\right.$ and $\rho$ ), bed height and diameter $\left(\mathrm{H}_{\mathrm{B}}\right.$ and $\left.\mathrm{d}_{\mathrm{B}}\right), \mathrm{CO}_{2}$ mass flow rate $\left(\mathrm{Q}_{\mathrm{CO} 2}\right)$, mass of feed (F) and solubility of the extract in the $\mathrm{CO}_{2}$ at the given pressure and temperature $\left(\mathrm{Y}^{*}\right)$. Some of these data were measured experimentally in this work: $\mathrm{X}_{0}, \mathrm{CO}_{2}$ mass flow rate, mass of feed, bed dimensions. For SFE from clove, solid density and solubility were available in literature [19]. For SFE from vetiver, solubility data was taken from results obtained by Favareto et al. [22] for phase equilibrium of the system $\mathrm{CO}_{2}+$ vetiver oil. Tables $\mathbf{1}$ and $\mathbf{2}$ show all data needed to apply the model.

Table 1. Process Parameters Obtained for SFE from Clove Buds

\begin{tabular}{|c|c|c|c|}
\hline Parameter & Small Scale & Constant v & Constant $\mathbf{t}_{\text {res }}$ \\
\hline \hline$\varepsilon(-)$ & 0.496 & 0.496 & 0.496 \\
\hline $\mathrm{X}_{0}(\mathrm{~kg}$ solute $/ \mathrm{kg}$ solid $)$ & 0.1353 & 0.1353 & 0.1353 \\
\hline$\rho_{\mathrm{s}}\left(\mathrm{kg} / \mathrm{m}^{3}\right)[19]$ & 1290 & 1290 & 1290 \\
\hline$\rho\left(\mathrm{kg} / \mathrm{m}^{3}\right)$ & 629 & 629 & 629 \\
\hline $\mathrm{Q}_{\mathrm{CO} 2} \times 10^{5}(\mathrm{~kg} / \mathrm{s})$ & 0.91 & 6.22 & 18.42 \\
\hline $\mathrm{H}_{\mathrm{B}}(\mathrm{m})$ & 0.0195 & 0.1200 & 0.0570 \\
\hline $\mathrm{d}_{\mathrm{B}}(\mathrm{m})$ & 0.0200 & 0.0545 & 0.0545 \\
\hline $\mathrm{F}(\mathrm{kg})$ & 0.00398 & 0.18196 & 0.08174 \\
\hline $\mathrm{Y}^{*}(\mathrm{~kg} \mathrm{oil} / \mathrm{kg} \mathrm{CO})$ \\
{$[19]$} & 0.23 & 0.23 & 0.23 \\
\hline $\mathrm{H}_{\mathrm{B}} / \mathrm{d}_{\mathrm{B}}(-)$ & 0.98 & 2.20 & 1.05 \\
\hline $\mathrm{F} / \mathrm{Q}_{\mathrm{CO} 2}(\mathrm{~kg} \mathrm{solid} . \mathrm{s} / \mathrm{kg}$ & 437.4 & 2925.4 & 443.8 \\
\hline $\left.\mathrm{CO}{ }_{2}\right)$ & & & \\
\hline $\mathrm{t}_{\mathrm{r} e s}(\mathrm{~s})$ & 211 & 1405 & 225 \\
\hline $\mathrm{v} \times 10^{5}(\mathrm{~m} / \mathrm{s})$ & 2.27 & 2.10 & 6.23 \\
\hline
\end{tabular}

\section{RESULTS AND DISCUSSION}

\section{Determination of the Global Yield}

The global yields obtained for SFE at the selected pressures and temperatures were $13.53 \%$ for clove buds and $5.83 \%$ for vetiver roots. These values were used as process parameters for the mathematical modeling of the OECs. 
Table 2. Process Parameters Obtained for SFE from Vetiver Roots

\begin{tabular}{|c|c|c|c|}
\hline Parameter & Small Scale & Constant $v$ & Constant $t_{\text {res }}$ \\
\hline$\varepsilon(-)$ & 0.702 & 0.699 & 0.704 \\
\hline $\mathrm{X}_{0}(\mathrm{~kg}$ solute/kg solid $)$ & 0.0583 & 0.0583 & 0.0583 \\
\hline$\rho_{\mathrm{S}}\left(\mathrm{kg} / \mathrm{m}^{3}\right)$ & 1300 & 1300 & 1300 \\
\hline$\rho\left(\mathrm{kg} / \mathrm{m}^{3}\right)$ & 829 & 829 & 829 \\
\hline $\mathrm{Q}_{\mathrm{CO} 2} \times 10^{5}(\mathrm{~kg} / \mathrm{s})$ & 1.42 & 10.50 & 28.33 \\
\hline $\mathrm{H}_{\mathrm{B}}(\mathrm{m})$ & 0.0290 & 0.0800 & 0.0800 \\
\hline $\mathrm{d}_{\mathrm{B}}(\mathrm{m})$ & 0.0200 & 0.0545 & 0.0545 \\
\hline $\mathrm{F}(\mathrm{kg})$ & 0.00354 & 0.07310 & 0.07197 \\
\hline $\mathrm{Y}^{*}(\mathrm{~kg} \mathrm{oil} / \mathrm{kg} \mathrm{CO})_{2}$ [22] & 0.04 & 0.04 & 0.04 \\
\hline $\mathrm{H}_{\mathrm{B}} / \mathrm{d}_{\mathrm{B}}(-)$ & 1.45 & 1.47 & 1.47 \\
\hline $\begin{array}{c}\mathrm{F} / \mathrm{Q}_{\mathrm{CO} 2}(\mathrm{~kg} \text { solid.s } / \mathrm{kg} \\
\left.\mathrm{CO}_{2}\right)\end{array}$ & 249.3 & 696.2 & 254.0 \\
\hline $\mathrm{t}_{\mathrm{res}}(\mathrm{s})$ & 533 & 1473 & 546 \\
\hline $\mathrm{v} \times 10^{5}(\mathrm{~m} / \mathrm{s})$ & 5.43 & 5.43 & 14.65 \\
\hline Yield in Line (\%) & 30.5 & 1.5 & 0.9 \\
\hline
\end{tabular}

\section{Extraction Kinetics}

\section{SFE from Clove Buds}

The model of Sovová [3] fitted well to experimental data of small scale SFE from clove buds, as one can observe in (Fig. 1). The extraction yields in the curves are presented in terms of ratio between extracted and extractable material.

The apparent discontinuities on the modeled curves, which can be observed in (Figs. 1 to 6), show the transition from the first to the second extraction period (see Equations 3 and 4). From this point, SFE rate begins to decrease.

Table 3 shows the values of the mass transfer coefficients adjusted with the model for small and large scale experiments. The low scale coefficients were used to predict OECs at large scale. (Figs. 2 and 3) show these simulations together with experimental and modeled large scale data, with constant velocity and residence time, respectively.

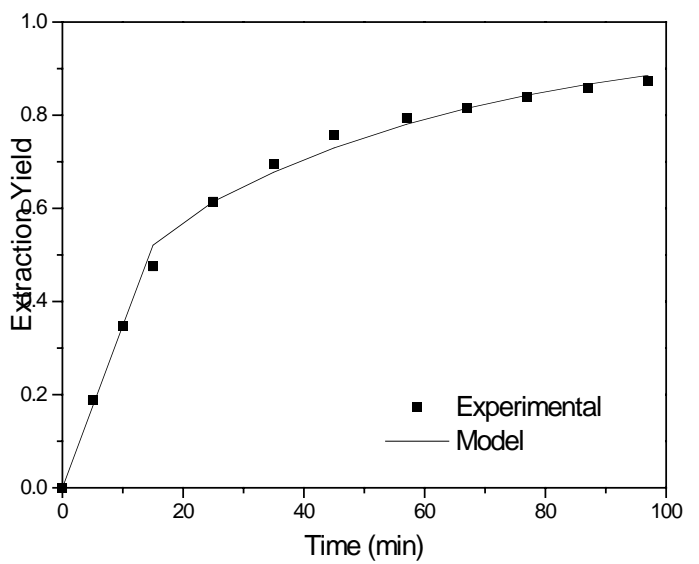

Fig. (1). Extraction curve of SFE from clove buds - small scale.

We can observe in Table 3 that the low scale mass transfer coefficients $\mathrm{k}_{\mathrm{YA}}$ and $\mathrm{k}_{\mathrm{XA}}$ are near the large scale ones, when residence time is kept constant. This results in a good OEC simulation, which is evident in the plot of (Fig. 3). Nevertheless, $\mathrm{k}_{\mathrm{YA}}$ and $\mathrm{k}_{\mathrm{XA}}$ are very different in the large scale with constant velocity, which leads to a bad scale-up simulation, as we can see in (Fig. 2). The value of $\mathrm{k}_{Y \mathrm{~A}}$ is much lower in the constant velocity large scale OEC, resulting in a lower extraction rate in the CER period. This can be observed by comparing the inclination of the modeled OECs of (Figs. $\mathbf{2}$ and $\mathbf{3}$ ).

These results indicate that the scale-up procedure is efficient when the residence time of the solvent in the extraction bed is kept constant, since the extraction kinetics could be reproduced in a twenty times larger scale, as seen in (Fig. 3). In addition, the method to increase the scale of the process keeping the same residence time seems to be clear: since bed density is constant, it is necessary to preserve the ratio between mass of raw material and solvent flow rate. Table $\mathbf{1}$ shows how this relation was practically conserved from the small scale experiment to this large scale experiment, which resulted in equal residence times.

In the scale-up with constant velocity, the main difference between the curves appears in the constant extraction rate (CER) period, where the extraction rate was quite lower. This can be observed clearly in (Fig. 2). However, the clove oil ratio in the solvent during this period was higher than in the other experiments, as shown in Table 1. Taking this into account, one reason for the lower extraction rates in the first scale-up trial seems to be the proportion between mass of raw material and solvent flow rate. This proportion was almost seven times higher than in the experiment with constant residence time, which indicates that the amount of $\mathrm{CO}_{2}$ used

Table 3. Mass Transfer Coefficients Calculated from the Model of Sovová

\begin{tabular}{|c|c|c|c|c|}
\hline \multirow{2}{*}{ Mass Transfer Coefficient } & \multicolumn{2}{|c|}{ SFE from Clove Buds } & \multicolumn{2}{|c|}{ SFE from Vetiver Roots } \\
\hline & Fluid Phase $k_{\mathrm{YA}}\left(\mathrm{s}^{-1}\right)$ & Solid Phase $k_{\mathrm{XA}}\left(\mathrm{s}^{-1}\right)$ & Fluid Phase $k_{\mathrm{YA}}\left(\mathrm{s}^{-1}\right)$ & Solid Phase $k_{\mathrm{XA}}\left(\mathrm{s}^{-1}\right)$ \\
\hline Small Scale Experiment & $2.72 .10^{-2}$ & $9.8 .10^{-3}$ & $4.94 .10^{-2}$ & $3.7 .10^{-3}$ \\
\hline Constant Velocity & $1.13 .10^{-2}$ & $6.2 .10^{-3}$ & $2.00 .10^{-2}$ & $5.6 .10^{-3}$ \\
\hline Constant Residence Time & $2.79 .10^{-2}$ & $8.1 .10^{-3}$ & $6.52 .10^{-2}$ & $1.14 .10^{-2}$ \\
\hline
\end{tabular}


was not enough to remove the clove oil at the same rate achieved in the small scale experiment.

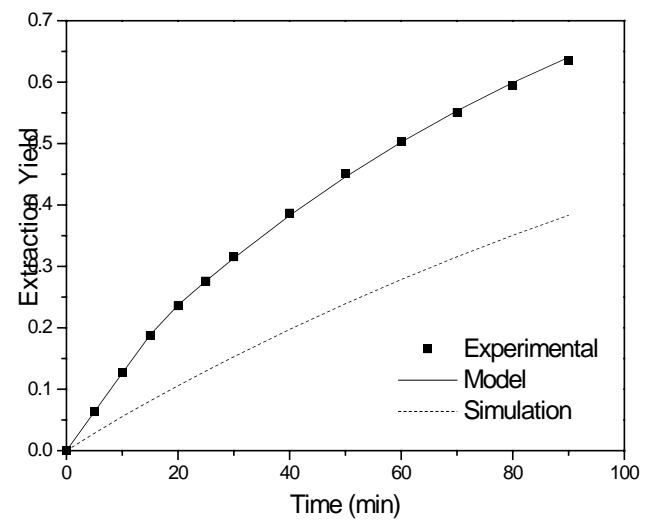

Fig. (2). SFE from clove buds - scale-up with constant velocity.

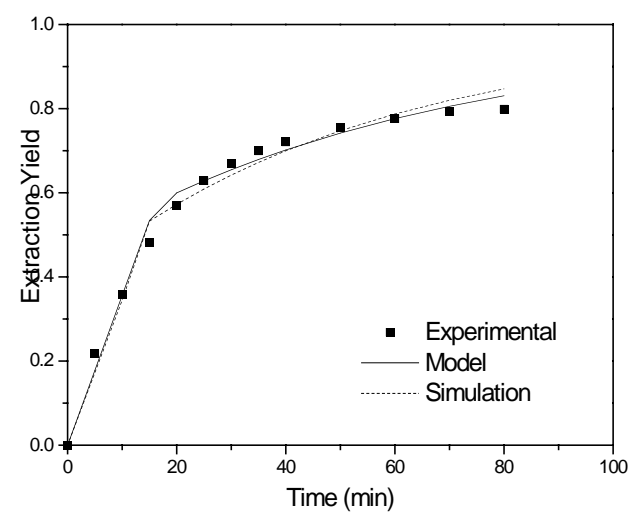

Fig. (3). SFE from clove buds - scale-up with constant residence time.

The analysis of the variation of the mass transfer coefficients with the $\mathrm{Q}_{\mathrm{CO} 2} / \mathrm{F}$ ratio suggests that there may be a correlation between these values. But we have few values in this work, and then we are not able to establish that correlation.

Another possible explanation for the effect of the $\mathrm{CO}_{2}$ flow rate is the result of the solvent velocity in the particle's mass transfer resistance: each solid particle in the extraction bed is recovered by a solute layer, which is reduced with the increase of velocity. In this case, the interstitial velocities seem to be high enough to deplete this layer, so the only diffusive mass transfer resistance occurs in the particle itself.

One possible reason for this difference in the SFE kinetics could be the preparation of the extraction bed of raw material. In this procedure, the clove bud particles could have been excessively compacted. As a result, preferential pathways could have been formed to the solvent, and part of the oil that should have been extracted by convection did not get in contact with $\mathrm{CO}_{2}$, or even needed a diffusive process to be extracted. These phenomena would have certainly resulted in lower extraction rates, and consequently, in lower mass transfer coefficient for the fluid phase, as happened in the scale-up trial with constant velocity. However, since the SFE bed's compacting was done exactly by the same way in order to keep the bed porosity constant in all cases, this problem did not affect the extraction kinetics. In the case of SFE from clove, the observation of the particle bed after the extraction can answer this question, since a SFE bed depleted from clove oil presents a color lighter than before SFE. Therefore, if there were preferential pathways, regions of different color intensities would be observed in the SFE bed after extraction. The SFE beds were observed after every extraction, and all of them were homogeneous with a light brown color, which shows that no preferential pathways were formed.

\section{SFE from Vetiver Roots}

The model of Sovová [3] provided good fittings to experimental SFE data from vetiver, as well as with clove. We can observe the model results in (Figs. 4 to 6), for small and large scale. The adjusted mass transfer coefficients are presented in Table $\mathbf{3}$.

The small scale mass transfer coefficients were used to simulate large scale OECs with constant velocity and constant residence time. The constant velocity scale-up was not effective, since the simulated OEC is far from experimental data. This result is observed in (Fig. 5). The difference between the mass transfer coefficients of small and large scale agree with the observed OECs. Once more, we have an indication that the $\mathrm{Q}_{\mathrm{CO} 2} / \mathrm{F}$ ratio should be preserved in order to reproduce small scale data in larger scale. We expected, then, that the scale-up with constant residence time, where $\mathrm{Q}_{\mathrm{CO} 2} / \mathrm{F}$ is preserved, lead an OEC similar to the experimental one.

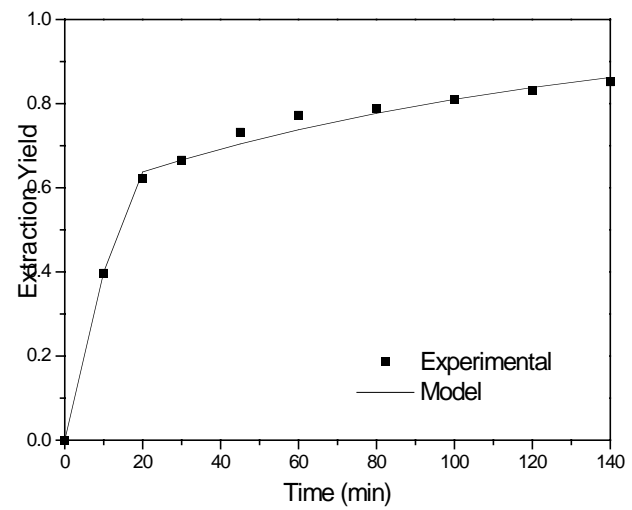

Fig. (4). Extraction curve of SFE from vetiver roots - small scale.

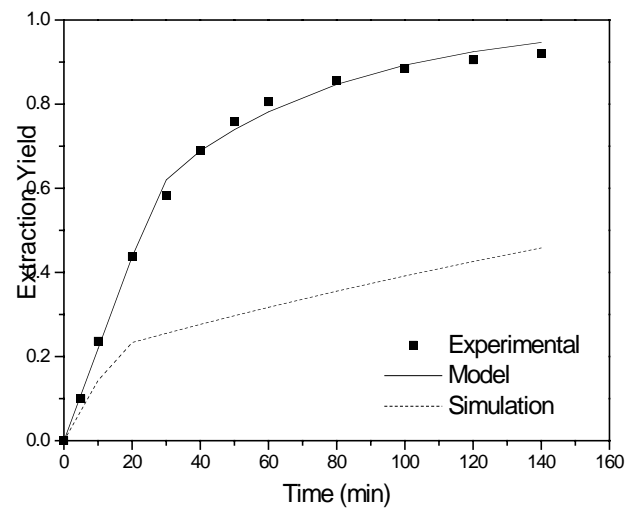

Fig. (5). SFE from vetiver roots - scale-up with constant velocity.

Fig. (6) shows the large scale simulation with constant residence time, compared with experimental and modeled large scale data. It is evident that this simulation is better that the constant velocity one, but it is not as good as that obtained with SFE from clove. The same result can be observed by comparing the mass transfer coefficients. 


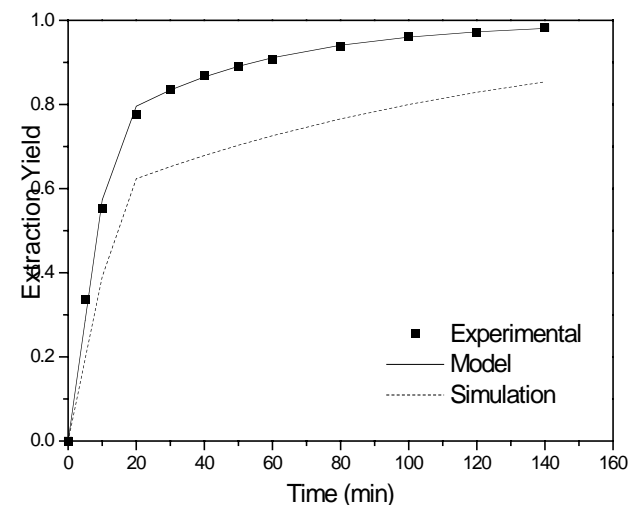

Fig. (6). SFE from vetiver roots - scale-up with constant residence time.

The values of $\mathrm{k}_{\mathrm{YA}}$ and $\mathrm{k}_{\mathrm{XA}}$ for the small scale experiment were lower than those of large scale with constant residence time, although similar values were expected, as observed with clove. The reasons for this difference, which lead to a bad large scale simulation, must be found. We can observe in (Figs. 4 and 6) that about $80 \%$ of the extractable material was recovered in the small scale run, while in large scale almost $100 \%$ was extracted. Then, for some reason, even after recovering the extract in the line after SFE, a significant amount of vetiver oil was not accounted in the OEC.

The first possible reason for this difference may be a significant loss of extract in parts of the equipment that were not washed, such as the column. Since small scale SFE from vetiver provides low extract amounts, the mass of oil that remains in the column may be important. Moreover, the physical properties of vetiver oil might have contributed to the low yield in small scale. Vetiver oil obtained by SFE is much more viscous than clove oil. Then, the transport properties were certainly affected. We must remember that the mass transfer coefficient can be calculated from the Sherwood number, which is a function of Reynolds, where viscosity is present. If vetiver oil affects the fluid phase viscosity, it shall probably change the kinetics of the process, leading to lower Reynolds and Sherwood numbers, and then to lower mass transfer coefficient and a different OEC. High solvent flow rates may be useful to avoid these problems, which did not appear in large scale SFE from vetiver.

We must notice that, according to Sovová [3], residence time should be preserved if we want to reproduce small scale OECs in large scale. This is implicit at the solution of the model, where the ratio between solvent flow rate and feed mass is present. This can be seen in Equations 3 to 10 .

\section{CONCLUSION}

In this work the results of scale-up SFE experiments using two different criteria are reported for two vegetable raw materials: clove buds and vetiver roots. In the case of clove, the scale-up was successful when keeping the same residence time of the solvent inside the SFE bed, as it is implicit in the model of Sovová [3]. Similar OECs and mass transfer coefficients were obtained for both small and large scale experiments. For SFE from vetiver roots, keeping constant residence time did not result in a successful scale-up. However, a significant accumulation of extract in the line during the SFE from vetiver at small scale was detected, which in- dicates that vetiver oil properties may affect the extraction kinetics and yield. The use of higher $\mathrm{CO}_{2}$ flow rates and consequently higher velocities in the SFE experiments may be an adequate solution to avoid these problems. This should make possible the evaluation of the scale-up criteria for SFE of viscous extracts, such as vetiver.

In both clove and vetiver oil SFEs, constant velocity scale-up did not lead to good simulated OECs. However, the values of the mass transfer coefficients and solvent to feed ratio suggest that there may be a correlation between them. More experimental data, at new solvent to feed ratios, are needed in order to establish this correlation. Such correlation may allow one to predict large scale processes, not only preserving residence time of the solvent inside the SFE bed.

\section{NOTATIONS}

$$
\begin{aligned}
& \text { A }=\text { Bed sectional area }\left(\mathrm{m}^{2}\right) \\
& \mathrm{d}_{\mathrm{B}}=\text { SFE bed diameter }(\mathrm{m}) \\
& \mathrm{F} \quad=\text { Feed mass }(\mathrm{kg}) \\
& \mathrm{H}_{\mathrm{B}} \quad=\text { SFE bed height }(\mathrm{m}) \\
& \mathrm{k}_{\mathrm{XA}}=\text { Mass transfer coefficient in the solid phase }\left(\mathrm{s}^{-1}\right) \\
& \mathrm{k}_{\mathrm{YA}}=\text { Mass transfer coefficient in the fluid phase }\left(\mathrm{s}^{-1}\right) \\
& \mathrm{m}=\text { Extract mass }(\mathrm{kg}) \\
& \mathrm{m}_{\mathrm{SI}}=\text { Mass of non-extractable material }(\mathrm{kg}) \\
& \mathrm{M}_{\mathrm{CER}}=\text { Extraction rate at the CER period }(\mathrm{kg} / \mathrm{s}) \\
& \text { OEC = Overall Extraction Curve } \\
& \mathrm{Q}_{\mathrm{CO} 2}=\text { Solvent flow rate }(\mathrm{kg} / \mathrm{s}) \\
& \mathrm{SFE}=\text { Supercritical Fluid Extraction } \\
& \mathrm{T}=\text { Extraction time }(\mathrm{s}) \\
& \mathrm{t}_{\mathrm{CER}}=\text { Constant extraction rate period }(\mathrm{s}) \\
& \mathrm{t}_{\mathrm{FER}}=\text { Falling extraction rate period }(\mathrm{s}) \\
& \mathrm{V}_{\mathrm{B}}=\text { Extraction bed volume }\left(\mathrm{m}^{3}\right) \\
& \mathrm{X}_{0} \quad=\text { SFE global yield }(\mathrm{kg} / \mathrm{kg}) \\
& \mathrm{X}_{\mathrm{p}} \quad=\text { Easily accessible solute ratio }(\mathrm{kg} / \mathrm{kg}) \\
& \mathrm{X}_{\mathrm{k}} \quad=\text { Intra-particle solute ratio }(\mathrm{kg} / \mathrm{kg}) \\
& \mathrm{W}=\text { Parameter of the model of Sovová }{ }^{3}(-) \\
& \mathrm{Y}^{*}=\text { Extract solubility }(\mathrm{kg} / \mathrm{kg}) \\
& \mathrm{Z}=\text { Parameter of the model of Sovová }{ }^{3}(-) \\
& \mathrm{Z} \quad=\text { Parameter of the model of Sovová }{ }^{3}(-) \\
& \varepsilon \quad=\text { Bed porosity (-) } \\
& \rho \quad=\text { Solvent density }\left(\mathrm{kg} / \mathrm{m}^{3}\right) \\
& \rho_{\mathrm{S}} \quad=\text { Solid density }\left(\mathrm{kg} / \mathrm{m}^{3}\right)
\end{aligned}
$$

\section{ACKNOWLEDGMENTS}

The authors wish to thank PRODOC-CAPES (046/02-7) and FAPESP (1999/01962-1 and 2001/14602-5) for financial support.

\section{REFERENCES}

[1] M. A. A. Meireles, "Supercritical extraction from solid: process design data (2001-2003)”, Curr. Opin. Solid St. M., vol. 7, pp. 321330, 2003. 
[2] M. M. Esquível, M. G Bernardo-Gil, and M. B. King, "Mathematical models for supercritical extraction of olive husk oil", J. Supercrit. Fluids, vol. 16(1), pp. 43-58, 1999.

[3] H. Sovová, "Rate of the vegetable oil extraction with supercritical $\mathrm{CO}_{2}$ - modeling of extraction curves", Chem. Eng. Sci., vol. 49(3), pp. 409-414, 1994.

[4] M. Goto, M. Sato, and T. Hirose, "Extraction of Peppermint Oil by Supercritical Carbon Dioxide”, J. Chem. Eng. Jpn., Vol. 26, pp. 401-409, 1993.

[5] J. Martínez, A. R. Monteiro, P. T. V. Rosa, M. O. M. Marques, and M. A. A. Meireles, "Multicomponent Model to Describe Extraction of Ginger Oleoresin with Supercritical $\mathrm{CO}_{2}$ ", Ind. Eng. Chem. Res., vol. 42, pp. 1057-1063, 2003.

[6] P. Manninen, J. Pakarinen, and H. Kallio, "Large-Scale Supercritical Carbon Dioxide Extraction and Supercritical Carbon Dioxide Countercurrent Extraction of Cloudberry Seed Oil", J. Agric. Food Chem. vol. 45, pp. 2533-2538, 1997.

[7] E. Dauksas, P. R. Venskutonis, and B. Sivik, "Extraction of Lovage (Levisticum officinale Koch.) by Carbon Dioxide. 1. Effect of $\mathrm{CO}_{2}$ Parameters on the Yield of the Extract", J. Agric. Food Chem., vol. 46, pp. 4347-4351, 1998.

[8] B. C. Roy, M. Goto, and T. Hirose, "Extraction of Ginger Oil with Supercritical Carbon Dioxide: Experiments and Modeling", Ind. Eng. Chem. Res., vol. 35, pp. 607-612, 1996.

[9] J. M. Del Valle, P. Napolitano, and N. Fuentes, "Estimation of Relevant Mass Transfer Parameters for the Extraction of Packed Substrate Beds Using Supercritical Fluids", Ind. Eng. Chem. Res., vol. 39, pp. 4720-4728, 2000.

[10] N. P. Povh, M. O. M. Marques, and M. A. A. Meireles, "Supercritical $\mathrm{CO}_{2}$ Extraction of Essential Oil and Oleoresin from Chamomile (Chamomilla recutita [L.] Rauschert)", J. Supercrit. Fluids., vol. 21, pp. 245-256, 2001.

[11] K. V. Menon, and S. R. Garg, "Inhibitory effect of clove oil in Listeria monocytogenes in meat and chese", Food Microbiol., vol. 18, pp. 647-650, 2001.

[12] W. Guan, S. Li, R. Yan, S. Tang, and C. Quan, "Comparison of essential oils of clove buds extracted with supercritical carbon di- oxide and other three traditional extraction methods", Food Chem., vol. 101(4), pp. 1558-1564, 2007.

[13] S. Arctander, Perfume and Flavor Materials of Natural Origin. Elizabeth, NJ, 1960.

[14] A. R. Chowdhury, D. Kumar, and H. Lohani, "GC-MS analysis of essential oils of Vetiveria zizanioides (Linn.) Nash. Roots", Fafai J., pp. 33-35, April-June 2002.

[15] P. Weyerstahl, H. Marschall, U. Splittgerber and D. Wolf, "New sesquiterpene ethers from Vetiver oil", Liebigs Ann., pp. 11951199, 1996.

[16] D. Baudoux, L'aromathérapie. Se soigner par les huiles essentielles. Amyris SPRL Editions, Bruxelles, Belgium., 2002.

[17] Societé Charabot. Available: http://www.charabot.fr/MP/mp gamme.asp [Accessed in March, 2003].

[18] C. Solomon, Encyclopedia of Asian Food. Periplus Editions, Boston, MA, 1998.

[19] V. M. Rodrigues, E. M. B. D. Souza, A. R. Monteiro, O. ChiavoneFilho, M. O. M. Marques, and M. A. A. Meireles, "Determination of the Solubility of Extracts from Vegetable Raw Material in Pressurized $\mathrm{CO}_{2}$ : a Pseudo-Ternary Mixture formed by Cellulosic Structure + Solute + Solvent", J. Supercrit. Fluids, vol. 22, pp. 2136, 2002.

[20] J. Martínez, P. T. V. Rosa, C. Menut, A. Leydet, P. Brat, D. Pallet, and M. A. A. Meireles, "Valorization of Brazilian Vetiver (Vetiveria zizanioides (L.) Nash ex Small) Oil", J. Agric. Food. Chem., vol. 52, pp. 6578-6584, 2004.

[21] J. Martínez, J. M. Martínez, P. T. V. Rosa, and M. A. A. Meireles, "Supercritical $\mathrm{CO}_{2}$ Extraction from Vetiver Roots: Modeling and Simulation of Extraction Curves", in I Iberoamerican Conference on Supercritical Fluids, 2007, pp. 42.

[22] R. Favareto, L. Cardozo-Filho, M. L. Corazza, P. T. V. Rosa, and M. A. A. Meireles, "Supercritical Fluid Extraction from Vetiver (Vetiveria zizanioides) roots: Kinetics and Phase Equilibrium", in VII Iberoamerican Conference on Phase Equilibria and Fluid Properties for Process Design, 2006, pp. 514-519. 